16 a 18 de outubro de 2019 - Campinas | Brasil

\title{
Uma análise cienciométrica sobre material particulado
}

\section{Jéssica C. D. Eulálio*, Danilo C. Nogarotto, Fabiana G. Barbosa, Simone A. Pozza.}

\section{Resumo}

O Material Particulado (MP) é um dos principais poluentes atmosféricos, e um dos que mais afetam a saúde humana, além da fauna e flora. Analisou-se, usando a cienciometria, trabalhos publicados que tenha como tema principal o MP. O levantamento de dados foi realizado pelas bases de dados Web of Science e Scopus, considerando trabalhos desenvolvidos no Brasil, publicados até 2017.

\section{Palavras-chave:}

MP10; MP2,5; Brasil

\section{Introdução}

O Material Particulado (MP) é o parâmetro mais comum ao se monitorar a qualidade do ar, representando a concentração de partículas suspensas. O MP engloba um conjunto de poluentes que se mantém suspenso na atmosfera em virtude de seu pequeno tamanho e apresenta potencial de causar efeitos deletérios a saúde humana, sendo que quanto menor o tamanho da partícula, maior seu potencial nocivo. As classificações mais utilizadas são: MP10 e MP2,5. MP10 são as partículas inaláveis com diâmetro menor ou igual a $10 \mu \mathrm{m}$ e o MP2,5 são as partículas inaláveis finas (ou respiráveis) que apresentam um diâmetro menor ou igual a $2.5 \mu \mathrm{m}$. A análise cienciométrica é usada para quantificar e identificar padrões, tendências e vieses das publicações dentro de um determinado assunto. Assim, o principal objetivo desse trabalho é analisar, por meio da cienciometria, artigos publicados até 2017, envolvendo estudos sobre o monitoramento outdoor do Material Particulado, realizados em território brasileiro, utilizando as bases de dados Web of Science e Scopus.

\section{Resultados e Discussão}

A Figura 1 mostra que 0 maior número de artigos publicados foi entre 2016 e 2017, sendo a frequência superior a 50. Ao analisar a tendência temporal dos estudos, foi possível identificar que a frequência de artigos, ao longo dos anos, segue a equação $y=0,001 x^{3}$ $0,035 x^{2}+0,312 x-0,327$, sendo possível determinar a tendência de crescimento nos próximos anos.

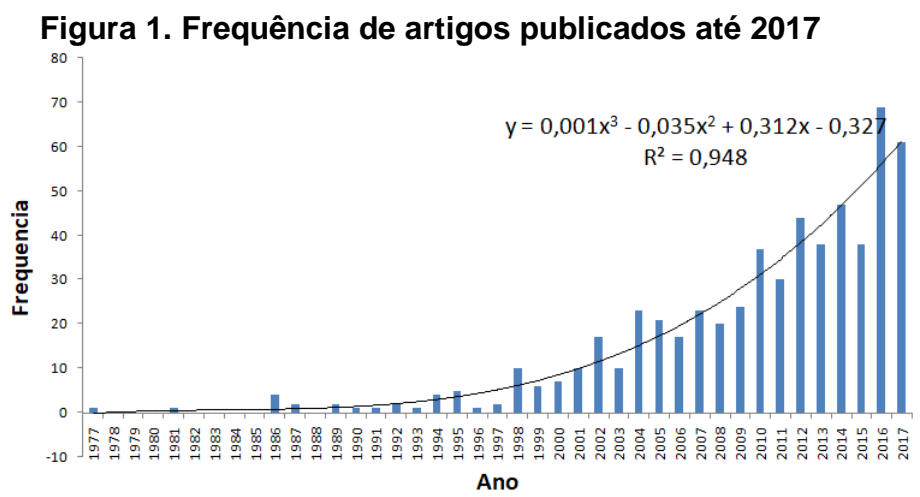

A Figura 2 mostra um percentual comparativo entre gêneros, no desenvolvimento de pesquisas científicas, relevando que até 1999 a participação das mulheres no científicas era muito inferior à participação dos homens. Nos últimos 17 anos, nota-se que o percentual de participação feminina alcançou valor próximo a equalização.

\section{Figura 2. Percentual de participação das mulheres}

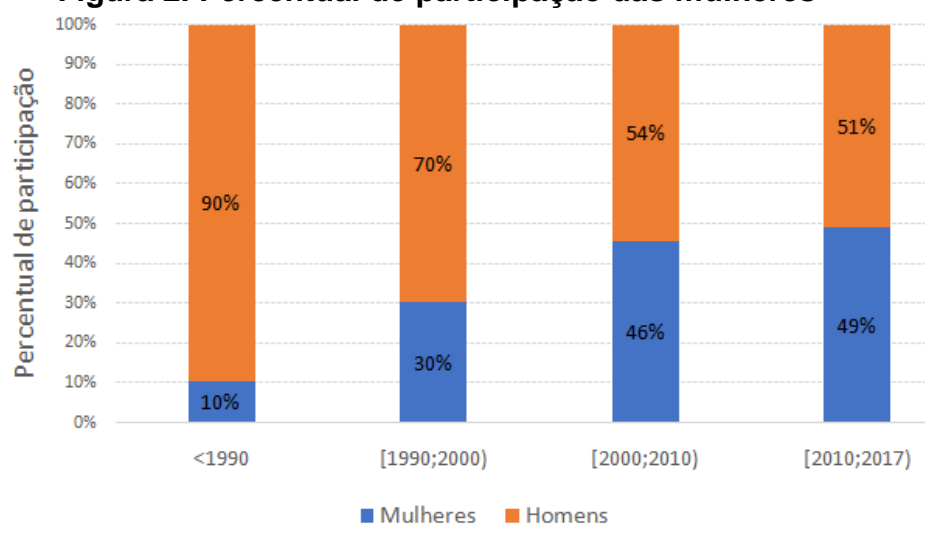

\section{Conclusões}

Por meio da análise cienciométrica, observou-se que o número de estudos realizados, em território brasileiro, sobre o material particulado cresceu ao longo dos anos, principalmente entre 2016-2017, com mais de 50 artigos publicados por ano. A participação das mulheres teve um destaque maior, no ambiente acadêmico, a partir do ano 2000, chegando nos últimos 7 anos a uma porcentagem próxima a dos homens.

\section{Agradecimentos}

Ao Conselho Nacional de Desenvolvimento Científico e Tecnológico (CNPq), pela concessão da bolsa de Iniciação Científica. 